\title{
Non-stationarity and internal correlations of the occurrence process of mining-induced seismic events
}

\author{
Dorota Olszewska $^{1}$ (D) Stanislaw Lasocki $^{1} \cdot$ Konstantinos Leptokaropoulos $^{1}$
}

Received: 2 January 2017/Accepted: 1 March 2017/Published online: 17 March 2017

(C) Institute of Geophysics, Polish Academy of Sciences \& Polish Academy of Sciences 2017. This article is an open access publication

\begin{abstract}
A point process, e.g., the seismic process, is potentially predictable when it is non-stationary, internally correlated or both. In this paper, an analysis of the occurrence process of mining-induced seismic events from Rudna copper mine in Poland is presented. Stationarity and internal correlation are investigated in complete seismic time series and segmentally in subseries demonstrating relatively stable seismicity rates. It is shown that the complete seismic series are non-stationary; however, most of their shorter subseries become stationary. In the stationary subseries, the distribution of interevent time is closer to the exponential distribution, which is characteristic for the Poisson process. However, in most of these subseries, the differences between the interevent time and Poisson distributions are still significant, revealing correlations among seismic events.
\end{abstract}

Keywords Stationary seismic process $\cdot$ Mining-induced seismicity $\cdot$ Internal correlations

\section{Introduction}

Among the various types of natural hazards, earthquakes constitute a phenomenon responsible for numerous casualties and huge socio-economic impact every year. The study of earthquakes has routinely been performed in two separate ways (e.g., Vere-Jones 2010): Physical modelling is based on the underlying physics of the seismogenic processes and accompanying effects, and stochastic

\footnotetext{
Dorota Olszewska

dolszewska@igf.edu.pl

1 Institute of Geophysics, Warsaw, Poland
}

modelling. This latter family of models includes a vast number of statistical algorithms and methodologies applied in both natural (e.g., Gardner and Knopoff 1974; Kiremidijan and Anagnos 1984) and induced (Baecher and Keeney 1982; Lasocki 1992a, b; 1993) seismicity. Stochastic models are increasingly applied since the last decades because of the development and installation of extensive and efficient networks resulting to high-quality seismic data in many sites worldwide.

If a seismic process is to be predictable, then it must be either non-stationary or internally correlated or both, i.e., it cannot be fully random. Gardner and Knopoff (1974) analysed the earthquake catalog of South California after removing aftershocks. They found that whereas the original catalog was non-Poissonian, after aftershock removal through declustering, it became Poissonian. This means that the seismic process of main-shocks occurrence was a stationary Poisson process, whereas the aftershock generation was highly dependent on time as well as the aftershock occurrences were correlated (interrelated). This phenomenon is still investigated in global catalogs (e.g., Lombardi and Marzocchi 2007) or for local seismicity (e.g., Gkarlaouni et al. 2015).

The need for improving the accuracy of seismic hazard assessment increases the interest in earthquake occurrence models, which assume some kind of time-dependence. Undoubtedly, an increase of seismological data quality, both in terms of completeness level and focal parameter accuracy, helps investigating this feature. In the specific case of mining-induced seismicity, the time-variation of mining operations leads to the time variability of the occurrence process of seismic events. Thus, its dependence on time is expected and was already studied elsewhere (e.g., Lasocki 1992a; Kijko 1997). The variability in time of seismicity is also considered in many studies carried out 
for mining areas (e.g., Lasocki and Orlecka-Sikora 2008). Lasocki (1992a) showed that mining seismic events do not constitute a Poisson process. However, the seismicity rates change slowly in time and the seismic process can be considered as stationary for short time periods ( $\sim 50$ days).

In the present paper, we study in detail the time series of seismic events from a mine for investigating properties of the event occurrence process. The study mining area is the Legnica-Głogów Copper District (LGCD) in southern Poland, where approximately 3.5 thousand events above local magnitude 1.0 (completeness of catalog is 1.2) are annually recorded. Occasional strong events, which may result in rockbursts, are a combined effect of the mining operations, natural and human-induced stresses, and interaction among the seismic events. Therefore, the seismic process due to time-varying mining activity is non-stationary and irregular, so the dependent fraction of seismicity is hard to be identified and removed by generic declustering algorithms. For this reason, the seismic series from specified time-space clusters of seismicity (in certain zones defined by Orlecka-Sikora and Lasocki 2002) were chosen and their stationary parts were selected for internal correlation study. The results are complemented with an uncertainty analysis.

\section{Methods and data used}

\section{Methods}

Interevent times of a stationary Poisson occurrence process follow the exponential distribution. The corresponding cumulative distribution function is:

$F(\tau)=1-\exp (-\lambda \tau)$,

where $\lambda$ is the constant mean event rate of the process.

We study here the coefficient of randomness in onedimensional space, $v$ (Matsumura 1984):
$v=\frac{E[X]^{2}}{E\left[X^{2}\right]}$,

where $E[X]$ is the first raw moment and $E\left[X^{2}\right]$ is the second raw moment of the interevent time distribution. For fully random occurrence process (a Poisson process), the ratio, $v$ equals:

$v=\frac{\int_{-\infty}^{+\infty} \tau \exp (-\lambda \tau) \mathrm{d} \tau}{\int_{-\infty}^{+\infty} \tau^{2} \exp (-\lambda \tau) \mathrm{d} \tau}=\frac{\left(\frac{1}{\lambda}\right)^{2}}{\left(\frac{2}{\lambda^{2}}\right)}=\frac{1}{2}$.

The process is regular when $v$ is greater than 0.5 and clustered when $v$ is smaller than 0.5 . In these cases, the interaction between events is present. In general, a repelling interaction leads to a regular pattern and attractive interaction leads to clustered pattern.

Confidence intervals of $v$ are assessed from estimates of this parameter from 1000 bootstrap replicas of the original data samples of interevent times. The limits of confidence intervals are evaluated as 5 and $95 \%$ percentiles. Thus, the analysis is performed on $95 \%$ confidence level.

The null hypothesis that the interevent time distribution is exponential is studied by means of the Anderson-Darling test (Stephens 1974). Its rejection indicates that the occurrence process in not a Poisson one.

The next estimated parameter is the Hurst exponent, $H$ (Hurst 1951), based on the classical rescaled range (R/S) analysis (for a detailed description of the method, see Lomnitz 1994 and the references therein). When a process does not possess long memory (has independent increments), $H$ equals 0.5 . The process has long memory and is persistent, when $H$ is greater than 0.5 , and is anti-persistent when $H$ is smaller than 0.5 . This parameter has been used to analyse long memory of natural (e.g., Correig et al. 1997; Xu and Burton 2006; Gkarlaouni et al. 2017) and induced seismic processes (e.g., Węglarczyk and Lasocki 2009). Here, we investigate the long memory property in the interevent time series. The statistical significance of the estimate $H$ is obtained, using the method from Wegglarczyk and Lasocki (2009).

Table 1 Parameters of the analysed series of mining events

\begin{tabular}{|c|c|c|c|c|}
\hline Event series & Time period of the series & $\begin{array}{l}\text { Magnitude median } \\
\text { and range }\end{array}$ & No. of events & $\begin{array}{l}\text { Activity rate (event } \\
\text { per month) }\end{array}$ \\
\hline Z_20.1 & 04 Apr. 1985-05 Sep. 2004 & $1.6[1.2-4.1]$ & 1245 & 5.4 \\
\hline Z_23.1 & 12 Apr. 1980-23 Sep. 2004 & $1.7[1.2-4.1]$ & 1592 & 5.4 \\
\hline Z_26 & 20 Nov. 1984-16 Sep. 2004 & $1.6[1.2-3.8]$ & 2678 & 11.3 \\
\hline Z_27 & 19 Apr. 1986-22 Sep. 2004 & $1.6[1.2-3.7]$ & 2207 & 10.0 \\
\hline Z_28 & 28 Mar. 1988-19 Sep. 2004 & $1.6[1.2-3.7]$ & 620 & 3.1 \\
\hline Z_30.1 & 27 Apr. 1990-18 May 2002 & $1.7[1.2-3.6]$ & 817 & 5.7 \\
\hline Z_31 & 01 Jan. 1980-20 Oct. 1990 & $1.5[1.2-3.5]$ & 2664 & 20.6 \\
\hline Z_35 & 26 Nov. 1991-11 Sep. 2004 & $1.7[1.2-3.7]$ & 711 & 4.6 \\
\hline
\end{tabular}




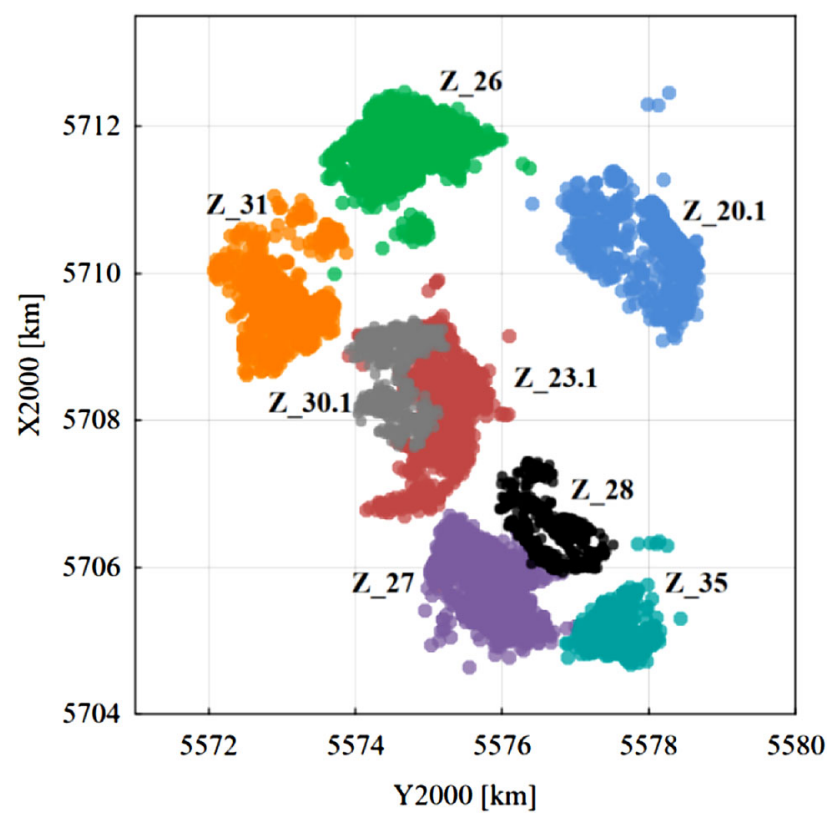

Fig. 1 Spatial distribution of the analysed clusters of mining events (both axes are in local coordinate system)

\section{Data}

The seismic catalog from 1984 up to 2004 of Rudna mine from Legnica Glogow Copper District (LGCD) of Poland was analysed. LGCD is a region in south-west of Poland where copper-ore is exploited from ore bearing layers at the depths between 900-1100 m. The underground mining in Rudna mine in the studied period induced 15.8 thousand of registered events from magnitude 0.9 up to 4.2 , so there were about 800 events per year.

Seismicity induced by mining forms distinct space-time clusters or space-time zones (Orlecka-Sikora and Lasocki 2002). In this paper, the analysis was done for 8 such clusters, which had different activity rates, maximum magnitudes, locations, and occurrence time periods (see Table 1; Figs. 1 and 2).

\section{Non-stationarity of the seismic event occurrence process}

Anderson-Darling (A-D) test was performed to test the null hypothesis that the distribution of interevent time was exponential. This distribution was significantly different than the exponential distribution in all analysed event series; in all cases, the $p$ values of the null hypothesis of A$\mathrm{D}$ test are smaller than $5 \times 10^{-4}$. This indicates that the background seismic processes were not Poissonian.

Next, the coefficients of randomness, $v$, were calculated and the Hurst exponents, $H$, were estimated for the analysed event series (Table 2). The coefficients of randomness are smaller than 0.5 for all series at the significance level 0.95 . The Hurst exponents for all cases are significantly greater than 0.5. However, these features as well as the misfit of the exponential distribution are most likely due to non-stationarity of the processes, which is clearly visible in Fig. 2.

To have a better insight into the process properties, we calculated the coefficients of randomness for the subseries formed by gradually removing smaller events from the initial event series. Figure 3 shows the changes of $v$ and the corresponding $90 \%$ confidence intervals as functions of the cutoff magnitude levels for the studied series. The minimum number of samples, for which $v$ were calculated, was set equal to 10 events. The coefficient of randomness tended to the value 0.5 when smaller events were removed. These results suggest that the process of generating stronger events is a stationary Poisson process or at least it is close to the Poisson process. Similar results and the same conclusion were presented by Lasocki (1992a). Such a 'self-randomization' of the series takes place for different cut-off magnitudes between 2.05 and 3.2. In two cases of Z_31 and Z_35 series, when the greatest cutoffs were applied, the coefficient of randomness became significantly greater than 0.5 , suggesting a regular behavior of the subseries.

The next part of the study was to check the extent of non-randomness in the studied data sets. For this purpose, the coefficient of randomness was calculated in sliding data windows which were being moved over the initial data series. The lengths of the windows were 300, 200, 100, and 50 events, consecutively, and the windows were advanced of 10 events in the first three cases of the window lengths and of 5 events for 50-event windows. Figure 4 shows $v$ and $90 \%$ confidence intervals calculated in the aforementioned sliding windows for series Z_27 and Z_28, as examples. The interevent times for shorter subseries tended to follow the exponential distribution; the shorter subseries were, the more of them exhibited the Poisson process property. However, even for the shortest considered subseries of 50 events, some traces of clustered or regular behavior remained. This indicates that some parts of the analysed series were so strongly non-stationary that they still exposed this feature even in the shortest fragments of the initial series. One can see in Fig. 4 that the 50 element subseries exhibited a regular behavior when the activity rate was growing and a clustered behavior when the activity rate was considerably irregular.

\section{Internal correlation of the tremors occurrence process}

The stationarity of the event series is an essential prerequisite for the studies of internal correlations, which occur when data show internal dependency like stress transfer, 

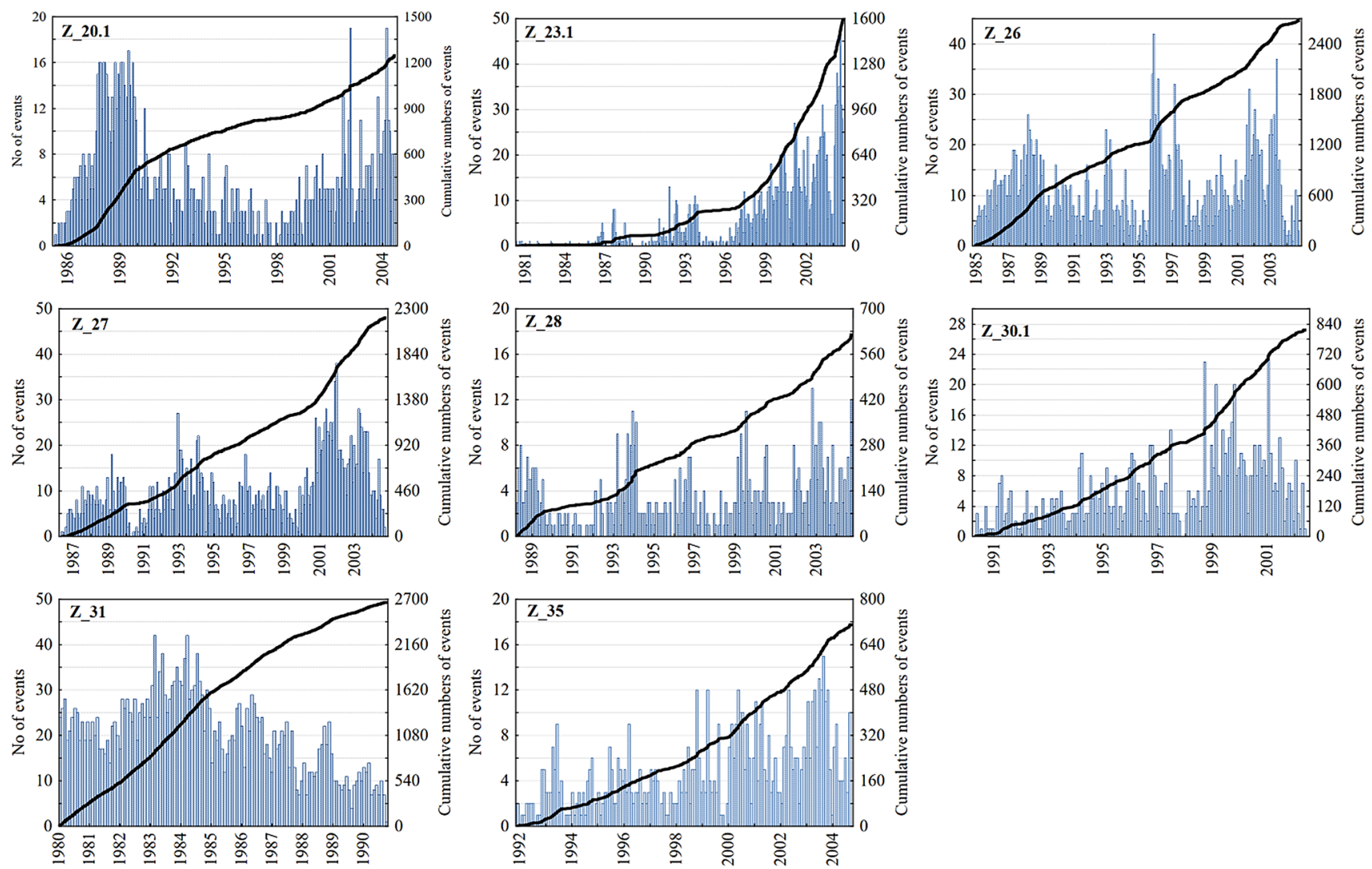

Fig. 2 Monthly activity rates (bars) and cumulative numbers of events (solid black) for the analysed event series

Table 2 Results of the analysis of the complete event series and the subseries created by removing smaller events

\begin{tabular}{llll}
\hline $\begin{array}{l}\text { Event } \\
\text { series }\end{array}$ & $\begin{array}{l}\text { The coefficient of } \\
\text { randomness } v \text { and } 90 \% \\
\text { confidence intervals }\end{array}$ & $\begin{array}{l}\text { Estimates of } \\
\text { Hurst } \\
\text { coefficient } \\
(H)\end{array}$ & $\begin{array}{l}\text { The lowest left-hand side limit of magnitude } \\
\text { range, in which the seismic process became a } \\
\text { stationary Poisson process }\end{array}$ \\
\hline Z_20.1 & $\mathbf{0 . 3 1}[\mathbf{0 . 2 7} ; \mathbf{0 . 3 6}]$ & $\mathbf{0 . 8 1}$ & 2.75 \\
Z_23.1 & $\mathbf{0 . 0 5}[\mathbf{0 . 0 4} ; \mathbf{0 . 0 8}]$ & $\mathbf{0 . 7 7}$ & 3.05 \\
Z_26 & $\mathbf{0 . 3 5}[\mathbf{0 . 3 1} ; \mathbf{0 . 3 8}]$ & $\mathbf{0 . 7 7}$ & 2.95 \\
Z_27 & $\mathbf{0 . 3 1}[\mathbf{0 . 2 7} ; \mathbf{0 . 3 7}]$ & $\mathbf{0 . 7 3}$ & 3.20 \\
Z_28 & $\mathbf{0 . 3 6}[\mathbf{0 . 3 3 ; 0 . 4 0 ]}$ & $\mathbf{0 . 8 3}$ & 2.55 \\
Z_30.1 & $\mathbf{0 . 3 2}[\mathbf{0 , 2 8 ; 0 , 3 6 ]}$ & $\mathbf{0 . 7 2}$ & 2.05 \\
Z_31 & $\mathbf{0 . 4 2}[\mathbf{0 . 3 7} ; \mathbf{0 . 4 7}]$ & $\mathbf{0 . 6 2}$ & 2.65 \\
Z_35 & $\mathbf{0 . 3 8}[\mathbf{0 . 3 5} ; \mathbf{0 . 4 1}]$ & $\mathbf{0 . 6 8}$ & 2.30
\end{tabular}

The values of coefficient of randomness and Hurst exponent, which significantly deviate from 0.5 , are in bold seasonality, etc. Therefore, to get insight into internal correlations of the studied seismic processes, we had to extract stationary subseries from the clearly non-stationary initial series. First, to do this, we made use of the results of above presented analysis of Matsumura coefficient of randomness in sliding windows. We extracted those fragments, for which the coefficients of randomness in consecutive windows did not deviate from the value 0.5 (under $90 \%$ confidence probability). The examples of such an extraction from series $Z \_27$ and $Z \_28$ are presented in Fig. 4 as light pink fields. The basic parameters of the extracted subseries are given in Table 3 .

The value 0.5 of the coefficient of randomness indicates fully random, that is also stationary behavior; therefore, the 

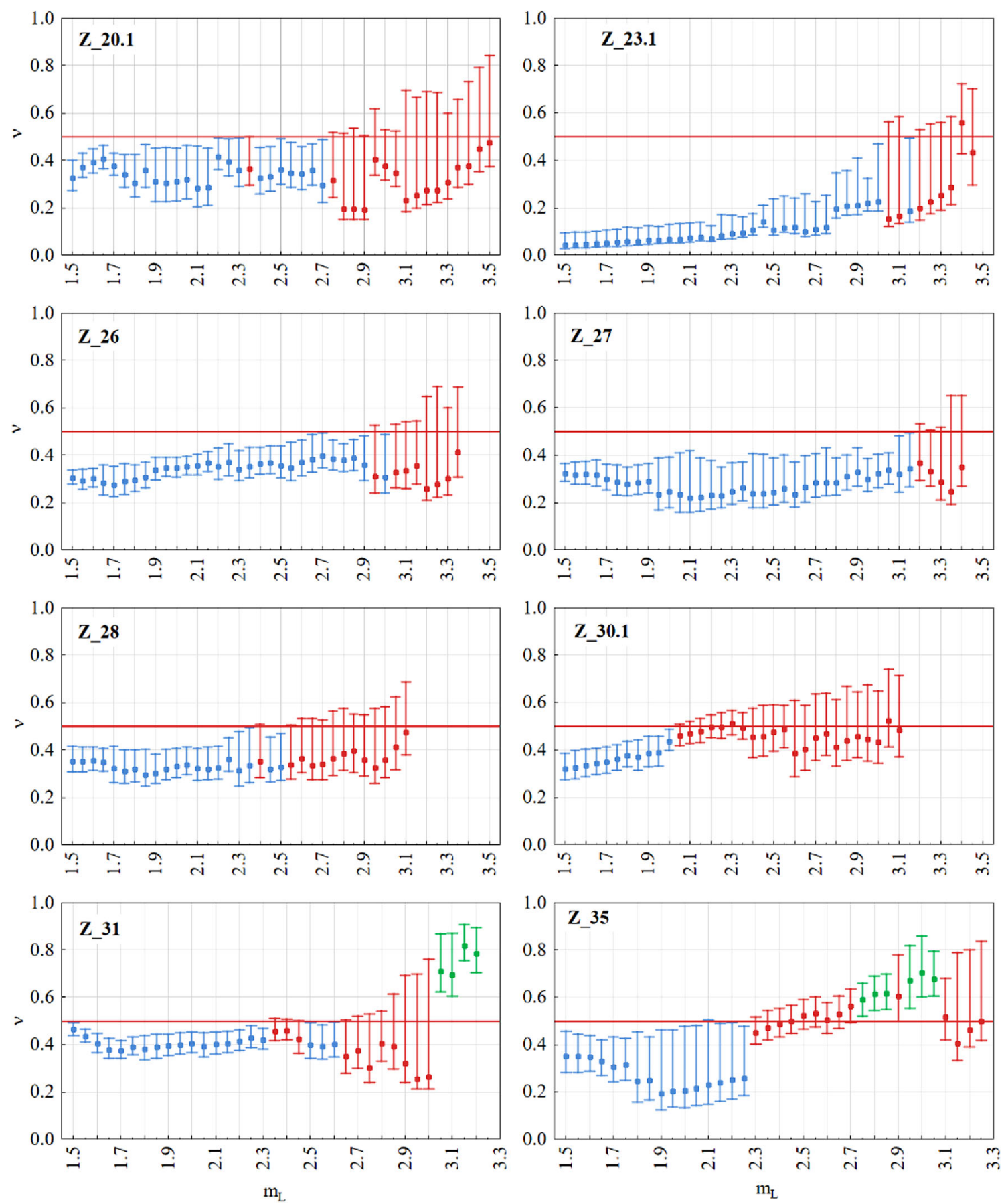

Fig. 3 Coefficient of randomness as a function of magnitude cut-off levels determining subseries of the initial event series. The vertical bars represent $90 \%$ confidence intervals of the coefficient and are in

blue for a clustered process, in red for a random process, and in green for a regular process

selected subseries were expected to be stationary. To confirm this conclusion, we tested the stationarity of the selected subseries be means of the Priestley-Subba Rao (PSR) test (Priestley and Subba Rao 1969). Contrary to the expectations, the test showed that the subseries were still non-stationary. The test $p$ value for the null hypothesis of stationarity was in all cases less than 0.015 . These results

evidence that the Matsumura coefficient of randomness is not sufficient to indicate by itself randomness of an event series in a one-dimensional case.

In this connection, we continued the selection of stationary subseries. Now, as a possible candidate for the stationary subseries, we were taking that fragment of the initial series, for which the coefficient of randomness was 
Fig. 4 Monthly activity rate of the event series Z_27 and Z_28 with coefficient of randomness for sliding windows comprising $300,200,100$, and 50-event subseries, respectively. The vertical bars represent $90 \%$ confidence intervals of the coefficient, and are in blue for a clustered process, in red for a random process, and in green for a regular process. Pink fields indicate the considered candidates for stationary subseries; magenta fields indicate the finally selected stationary subseries See: text for further explanations
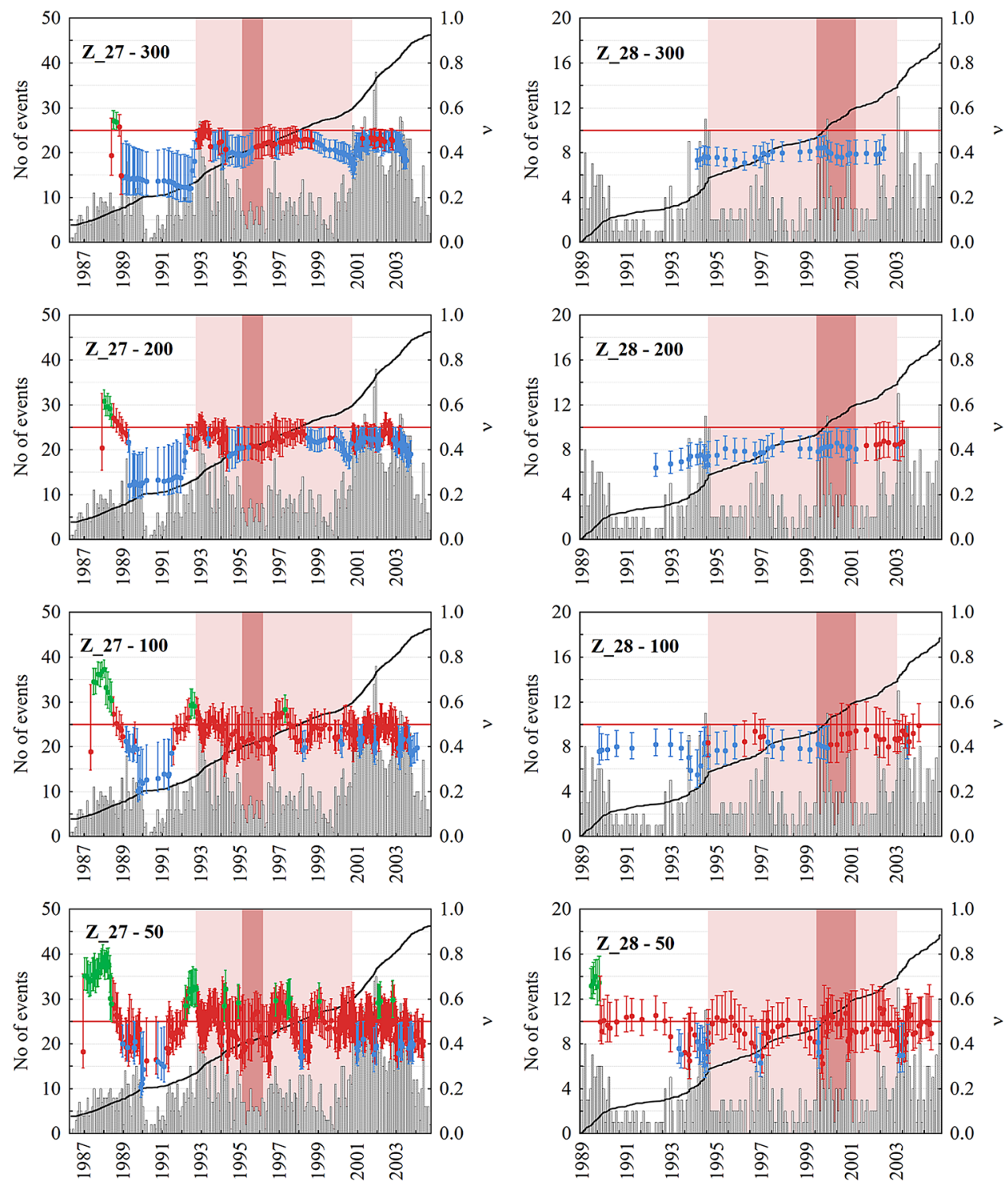

close to 0.5 but also maintained relatively stable values. The candidate could not have also gaps in the seismic activity, which we ascertained through a visual inspection of the histogram of seismic activity for the candidate. Finally, we checked the stationarity of the newly selected subseries by means of the PSR test. All the newly selected subseries turned to be stationary. However, the sizes of the subseries were considerably reduced, which is illustrated by magenta fields in Fig. 4. Basic parameters of these newly selected stationary subseries are given in Table 4 .

The A-D test was applied to the stationary subseries to check the exponentiality of the interevent time distribution. The test results are shown in Table 5. In six out of eight studied cases, the null hypothesis on exponentiality was turned down at the significance level 0.05 . In the remaining two cases of the subseries ssZ_20.1 and ssZ_28, the A-D test did not indicate significant deviations of interevent time distribution from the exponential distribution at the prescribed significance level.

As shown in Table 5, in all eight cases, the $90 \%$ confidence intervals of $v$ included 0.5 - the value characteristic for a fully random Poisson process. It, therefore, could not be excluded that the event occurrence process was Poissonian. At the same time, the A-D test rejected the hypothesis on exponentiality of the interevent time, i.e., turned down the hypothesis that the occurrence process was Poissonian in six out of eight cases. To interpret these seemingly ambiguous results, we recall the inherent property of hypotheses testing. A null hypothesis can be either rejected at a prescribed significance level-the alternative hypothesis is true, or the null hypothesis cannot be rejected, which does not mean that the null hypothesis is true. In 
Table 3 Parameters of the subseries, which were thought to be stationary based on the results of coefficient of randomness analysis in sliding windows

\begin{tabular}{|c|c|c|c|c|}
\hline $\begin{array}{l}\text { Subseries } \\
\text { name }\end{array}$ & Time period of the subseries & $\begin{array}{l}\text { Magnitude median } \\
\text { and range }\end{array}$ & $\begin{array}{l}\text { No. of } \\
\text { events }\end{array}$ & $\begin{array}{l}\text { Activity rate (events } \\
\text { per month) }\end{array}$ \\
\hline sZ_20.1 & 31 Oct. 1989-22 Nov. 1992 & $1.6[1.2-2.8]$ & 193 & 5.3 \\
\hline sZ_23.1 & 03 Mar. 1998-09 Sep. 2003 & $1.7[1.2-4.1]$ & 910 & 14.0 \\
\hline sZ_26 & 09 Oct. 1988-28 Aug. 1995 & $1.7[1.2-3.6]$ & 658 & 8.0 \\
\hline sZ_27 & 17 Sep. 1992-28 Sep. 2000 & $1.7[1.2-3.7]$ & 854 & 8.9 \\
\hline sZ_28 & 03 Fab. 1994-07 Oct. 2002 & $1.6[1.2-3.6]$ & 287 & 2.8 \\
\hline sZ_30.1 & 03 Aug. 1991-04 Sep. 1998 & $1.8[1.2-3.3]$ & 364 & 4.3 \\
\hline sZ_31 & 09 Jan. 1985-20 Oct. 1990 & $1.7[1.2-3.5]$ & 1074 & 15.5 \\
\hline sZ_35 & 26 Nov. 1991-24 Sep. 1998 & $1.8[1.2-3.7]$ & 254 & 3.1 \\
\hline
\end{tabular}

Table 4 Parameters of the finally selected stationary subseries, which were used in the internal correlation study

\begin{tabular}{|c|c|c|c|c|}
\hline $\begin{array}{l}\text { Sub series } \\
\text { name }\end{array}$ & $\begin{array}{l}\text { Time period of the } \\
\text { subseries }\end{array}$ & $\begin{array}{l}\text { Magnitude median and } \\
\text { range }\end{array}$ & $\begin{array}{l}\text { No. of } \\
\text { events }\end{array}$ & $\begin{array}{l}\text { Activity rate (events per } \\
\text { month) }\end{array}$ \\
\hline ssZ_20.1 & $\begin{array}{l}25 \text { Sep. 1991-16 May. } \\
1994\end{array}$ & $1.6[1.2-3.5]$ & 121 & 3.8 \\
\hline ssZ_23.1 & $\begin{array}{l}01 \text { Oct. 1990-14 Aug. } \\
2000\end{array}$ & $1.7[1.2-3.7]$ & 265 & 13.9 \\
\hline ssZ_26 & $\begin{array}{l}04 \text { Apr. 1989-13 Feb. } \\
1991\end{array}$ & $1.7[1.2-3.4]$ & 197 & 8.8 \\
\hline ssZ_27 & $\begin{array}{l}\text { 08 Feb. 1995-09 Mar. } \\
1996\end{array}$ & $1.7[1.2-3.6]$ & 79 & 6.1 \\
\hline ssZ_28 & $\begin{array}{l}20 \text { Jan. 1999-18 Nov. } \\
2000\end{array}$ & $1.5[1.2-3.2]$ & 97 & 4.4 \\
\hline ssZ_30.1 & $\begin{array}{l}16 \text { Jun. 1994-14 Jun. } \\
1995\end{array}$ & $1.6[1.2-3.2]$ & 64 & 5.4 \\
\hline ssZ_31 & $\begin{array}{l}\text { 10 Jan. 1985-25 May } \\
1986\end{array}$ & $1.5[1.2-3.1]$ & 348 & 21.2 \\
\hline ssZ_35 & $\begin{array}{l}27 \text { Aug. 1995-26 Apr. } \\
1997\end{array}$ & $1.9[1.2-3.1]$ & 76 & 3.8 \\
\hline
\end{tabular}

Table 5 Results of the analyses of the stationary parts of event series

\begin{tabular}{lllll}
\hline $\begin{array}{l}\text { Event } \\
\text { series }\end{array}$ & $\begin{array}{l}\text { PSR test results } \\
p \text { value for H0: } \\
\text { stationarity }\end{array}$ & $\begin{array}{l}\text { A-D test results } \\
p \text { value for H0: } \\
\text { exponentiality }\end{array}$ & $\begin{array}{l}\text { The coefficient of } \\
\text { randomness } v \text { and its } \\
90 \% \text { confidence intervals }\end{array}$ & $\begin{array}{l}\text { Hurst coefficient, } H \text { and the 5\% } \\
\text { critical value for H0: the process } \\
\text { does not have long memory }\end{array}$ \\
\hline ssZ_20.1 & 0.23 & 0.1408 & $0.46[0.40 ; 0.54]$ & $0.70 ; 0.72$ \\
ssZ_23.1 & 0.12 & $\mathbf{0 . 0 0 0 5}$ & $0.49[0.45 ; 0.52]$ & $0.57 ; 0.67$ \\
ssZ_26 & 0.62 & $\mathbf{0 . 0 0 0 5}$ & $0.47[0.42 ; 0.52]$ & $0.60 ; 0.69$ \\
ssZ_27 & 0.26 & $\mathbf{0 . 0 0 8 9}$ & $0.45[0.36 ; 0.58]$ & $0.63 ; 0.77$ \\
ssZ_28 & 0.19 & 0.9836 & $0.50[0.44 ; 0.58]$ & $0.51 ; 0.75$ \\
ssZ_30.1 & 0.53 & $\mathbf{0 . 0 0 0 5}$ & $0.50[0.44 ; 0.58]$ & $0.55 ; 0.83$ \\
ssZ_31 & 0.21 & $\mathbf{0 . 0 0 3 9}$ & $0.52[0.49 ; 0.55]$ & $0.55 ; 0.66$ \\
ssZ_35 & 0.12 & $\mathbf{0 . 0 3 3 6}$ & $0.48[0.43 ; 0.57]$ & $0.45 ; 0.38$
\end{tabular}

The values, which lead to rejection of the respective null hypothesis, are in bold

case when it cannot be rejected, it is either true or a combination of the sample representativeness and the verification method is not powerful enough to reject this hypothesis. Only the rejection of the null hypothesis is truly conclusive, the opposite leaves the inference in an 'unknown' state. In this connection, we accept the results of 
the A-D test. Based on its results, we conclude that the earthquake occurrence process in mines even in its stationary parts can be and more often is non-Poissonian (not fully random).

In the last part of the analysis, we estimated Hurst exponent and the 95\% critical values for the null hypothesis that the interevent time series did not have long memory. The values of Hurst exponent, shown in Table 5, in neither case differed significantly from the respective values indicating lack of the long memory property. However, this might be due to shortness of the stationary subseries.

\section{Conclusions}

Our analysis evidences that interevent times in the studied series of seismic events induced by mining do not follow an exponential distribution. The background seismic process is not a stationary Poisson process.

The time dependency of the seismic process is visible in series, which contain smaller, numerous events. Series comprising only stronger events exhibit stationarity. This indicates the importance of keeping the completeness levels of seismic systems as low as possible, because information on variability of a seismic process in time is the necessary condition for prediction.

The studied seismic process turns out to be non-stationary, but its time variability is slow. Shorter subseries of the initial series cease to exhibit this non-stationarity, and most of the 50 elements subseries look like drawn from stationary processes. The slow variability in time of the seismic process makes it possible to estimate time-dependent process parameters by means of moving data windows technique.

In stationary segments of the initial seismic series, the interevent time distributions are closer to the exponential distribution, but most of them are still not exponential. The occurrence process is not a Poisson process, which suggests indirectly that the process is internally correlated. These internal correlations do not seem to have a long rangethey are not confirmed by the R/S analysis. However, the results of $\mathrm{R} / \mathrm{S}$ analysis are uncertain, because the stationary segments were short.

In overall, in seismic hazard assessments in the first approximation, such stationary segments (windows) can be regarded as outcomes of Poisson processes. However, more detailed insights into the seismic hazard in mines require further studies of the nature of correlations among seismic events to account for these correlations in hazard analyses.

Acknowledgements This work was supported within statutory activities No 3841/E-41/S/2017 of the Ministry of Science and Higher Education of Poland.
Open Access This article is distributed under the terms of the Creative Commons Attribution 4.0 International License (http://crea tivecommons.org/licenses/by/4.0/), which permits unrestricted use, distribution, and reproduction in any medium, provided you give appropriate credit to the original author(s) and the source, provide a link to the Creative Commons license, and indicate if changes were made.

\section{References}

Baecher GB, Keeney RL (1982) Statistical examination of reservoirinduced seismicity. Bull Seismol Soc Am 72:553-569

Correig AM, Urquizu M, Vila J, Marti J (1997) Analysis of temporal occurrence of seismicity at Deception Island (Antarctica): a nonlinear approach. Pure Appl Geophys 149:553-574. doi:10. 1007/s000240050041

Gardner JK, Knopoff L (1974) Is the sequence of earthquakes in southern California, with aftershocks removed, Poissonian? Bull Seismol Soc Am 64:1363-1367

Gkarlaouni C, Lasocki S, Papadimitriou E, Tsaklidis G (2017) Hurst analysis of seismicity in Corinth rift and Mygdonia graben (Greece). Chaos Solitons Fractals 96:30-42. doi:10.1016/j.chaos. 2017.01.001

Hurst H (1951) Long term storage capacity of reservoirs. Trans Am Soc Civ Eng 116:770-799

Kijko A (1997) Keynote lecture: seismic hazard assessment in mines. In: Gibowicz SJ, Lasocki S (eds) Rockburst and seismicity in mines. Rotterdam, Balkama, pp 247-256

Kiremidijan AS, Anagnos T (1984) Stochastic slip predictable model for earthquake occurrences. Bull Seismol Soc Am 74:739-755

Lasocki S (1992a) Non-poissonian structure of mining induced seismicity. Acta Mont 84:51-58

Lasocki S (1992b) Weibull distribution for time intervals between mining tremors. Publs Inst Geophys Pol Acad Sci 16(245):241-260

Lasocki S (1993) Weibull distribution as a model for sequence of seismic events induced by mining. Acta Geophys Pol 41:101-112

Gkarlaouni C, Lasocki, S, Papadimitriou E (2015) Investigation of earthquake magnitude and interevent time distribution in Corinth Gulf and Mygdonia basin with the use of stochastic tools. In: Proceedings of the 28th panhellenic statistics conference. Greek Statistical Institute, pp 385-399

Lasocki S, Orlecka-Sikora B (2008) Seismic hazard assessment under complex source size distribution of mining-induced seismicity. Tectonophysics 456:28-37. doi:10.1016/j.tecto.2006.08.013

Lombardi AM, Marzocchi W (2007) Evidence of clustering and nonstationarity in the time distribution of large worldwide earthquakes. J Geophys Res 112:B02303. doi:10.1029/ 2006JB004568

Lomnitz C (1994) Fundamentals of earthquake prediction. Willey, New York

Matsumura S (1984) A one-parameter expression of seismicity patters in space and time. Bull Seismol Soc Am 74:2559-2576

Orlecka-Sikora B, Lasocki S (2002) Clustered structure of seismicity from the Legnica-Glogow copper district. Publ Inst Geophys Pol Acad Sci 24(340):105-119 (in Polish with English abstract)

Priestley MB, Subba Rao T (1969) A test for non-stationarity of timeseries. J R Stat Soc Ser B (Methodol) 31(1):140-149

Stephens MA (1974) EDF statistics for soodness of fit and some comparisons. J Am Stat Assoc 69:730-737

Vere-Jones D (2010) Foundations of statistical seismology. Pure Appl Geophys 167:645-653 
Węglarczyk S, Lasocki S (2009) Studies of short and long memory in mining-induced seismic processes. Acta Geophys 57:696-715. doi:10.2478/s11600-009-0021-x
Xu Y, Burton PW (2006) Time varying seismicity in Greece: Hurst's analysis and Monte Carlo simulation applied to a new earthquake catalogue for Greece. Tectonophysics 423:125-136. doi:10.1016/j.tecto.2006.03.006 